\title{
Correlation Between Epicardial Fat Thickness and Cardiovascular Risk in Hemodialysis Patients
}

\author{
Ashraf Abd El-Khalik Barakat ${ }^{1}$, Fatma Mohammed Nasr ${ }^{1}$, Amna Ahmed Metwaly ${ }^{1}$, \\ Manar Abd El-Rouf Raafat Ameen ${ }^{2}$
}

${ }^{1}$ Intensive Care Department, Theodor Bilharz Research Institute, Cairo, Egypt

${ }^{2}$ Nephrology Department, Theodor Bilharz Research Institute, Cairo, Egypt

\section{Email address:}

dr.ashraf.a@hotmail.com (A. A. El-Khalik B.), fatma_elwakeel@live.com (F. M. Nasr), amnametwaly@ hotmail.com (A. A. Metwaly), manar_raafat@hotmail.com (M. A. El-Rouf R. A.)

\section{To cite this article:}

Ashraf Abd El-Khalik Barakat, Fatma Mohammed Nasr, Amna Ahmed Metwaly, Manar Abd El-Rouf Raafat Ameen. Correlation Between Epicardial Fat Thickness and Cardiovascular Risk in Hemodialysis Patients. American Journal of Internal Medicine.

Vol. 3, No. 3, 2015, pp. 86-94. doi: 10.11648/j.ajim.20150303.12

\begin{abstract}
Background: Cardiovascular diseases are common in hemodialysis (HD) patients and cardiovascular mortality is responsible for $50 \%$ of overall deaths in these patients. Epicardial fat thickness (EpFT) may be an effective marker for the prediction of cardiovascular diseases in hemodialysis patients. The thickness of EpF can be measured by echocardiography that can accurately estimate the actual amount of EpF. The aim of the current study is to assess the association between EpFT and carotid intima-media thickness (CIMT), left ventricular systolic and diastolic function and left ventricular mass index in patients with chronic kidney disease (CKD) undergoing hemodialysis to clarify the relationships between EpF and cardiovascular disease risk in these patients. Materials and Methods: Forty adult uremic patients from dialysis unit and twenty (age and sex matched) healthy control subjects were included in this study. Clinical evaluation, routine laboratory investigations, echocardiographic study including measurement of EpFT and carotid Duplex to estimate CIMT were done to all subjects. Results: we found highly significant increase in serum C-reactive protein and significant increase in serum phosphorus and triglyceride with significant decrease in serum calcium and high-density lipoprotein cholesterol in hemodialysis patients compared to the controls. Also, there were significant increases in left ventricular mass index, left atrium diameter, carotid intima-media thickness, epicardial fat thickness, peak velocity of the late filling wave due to atrial contraction (A wave) and deceleration time of $\mathrm{E}$ wave in hemodialysis patients compared to the controls. There were also highly significant decrease in E/A ratio in hemodialysis patients compared to healthy control subjects. EpFT measured by echocardiography in hemodialysis patients was positively correlated with body mass index, CRP, left atrium diameter, left ventricular mass index, deceleration time and CIMT and negatively correlated with high-density lipoprotein cholesterol and E/A ratio. Conclusion: Hemodialysis patients can be evaluated routinely by echocardiography for early detection of cardiovascular structural and functional changes which are common in these patients and epicardial fat thickness is an effective marker for the prediction of cardiovascular risk in hemodialysis patients.
\end{abstract}

Keywords: Hemodialysis Patients, Cardiovascular Diseases, Carotid Intima-Media Thickness, Epicardial Fat Thickness

\section{Introduction}

Chronic kidney disease (CKD) is highly prevalent affecting roughly $7 \%$ of the general adult population and up to one in three elder individuals [1]. Indeed cardiovascular mortality is responsible for $50 \%$ of overall deaths and is up to 20 times more incident in CKD individuals than in the general population [2]. Coronary artery calcification (CAC), a marker of subclinical vascular disease that is highly prevalent in CKD, reliably predicts the risk for overall mortality and cardiovascular events in dialytic $[3,4]$ as well as in non-dialytic patients $[5,6]$.

Decreased glomerular filtration rate (GFR) and proteinuria were both found to be independently associated with coronary artery disease (CAD) [7-9]. The risk for CAD increases gradually with the decline of glomerular filtration 
rates; that means that end-stage renal failure (ESRF) patients have the highest CVD risk among CKD population [10-13].

Atherosclerosis is a condition characterized with formation of plaques on the intimal layer of the vessels. Coronary atherosclerotic plaques constitute most of the vascular diseases in general population [14]. However, the pathophysiology of vascular disease in CKD is quite different from that related to atherosclerosis, in the general population [15]. Beside traditional risk factors including hypertension, diabetes, dyslipidemia, and advanced age, novel risk factors such as endothelial dysfunction, CKD abnormalities (hyperphosphatemia, hyperparathyroidism, and vascular calcifications), increased oxidative stress, and inflammation are highly prevalent and seem to play a more important role for vascular disease in CKD and ESRF patients compared to healthy subjects [16-19].

The spectrum of cardiovascular disease in CKD not only involves coronary artery disease, but also involves other disease states such as chronic heart failure, sudden death, and arrhythmias [20].

Left ventricular diastolic disease (LVDD) would be expected more frequently among patients with end stage renal disease (ESRD) than in the general population due to the inflammation, fluid overload, hypertension, reninangiotensin-aldosterone system activation, and LV hypertrophy associated with ESRD [21\& 22]. Abnormal fat distribution seems a likely culprit for the high prevalence of LVDD in patients undergoing dialysis. Such patients tend to have higher amounts of visceral adipose tissue associated with low-grade inflammation, which leads in turn to subclinical LVDD [23]. Epicardial fat $(\mathrm{EpF})$ is characterized by a high rate of release of free fatty acids (FFA) [24], which encounter no physical barrier or fascia before reaching the cardiomyocytes [25]; therefore, the myocardium receives a double dose of FFA from both the EpF and the systemic circulation.

Visceral adipose tissue is highly metabolically active and produces hormones and cytokines, including those with antiatherosclerotic properties (e.g. adiponectin [26]) and those with pro-atherosclerotic properties (e.g. Interleukin-6 (IL-6) and tumor necrosis factor $\alpha$ ) [27]. Epicardial fat, a visceral deposit of adipose tissue located between the myocardium and visceral pericardium, is also metabolically active and produces many of the same pro-atherogenic cytokines found in visceral abdominal fat [25\&28]. In patients with end stage kidney disease requiring dialysis, the total volume of epicardial fat is correlated with CAD [29], and is significantly greater in dialysis patients versus healthy controls [30].

Epicardial fat thickness (EpFT) is strongly associated with increased left ventricular mass (LVM) [31] documented by both autopsy and echocardiography [32\&33]. Iacobellis et al. reported that this association was independent of systolic and diastolic blood pressure [33].

Epicardial fat can be assessed with computed tomography (CT), magnetic resonance imaging (MRI) and echocardiography. While CT and MRI have better image quality than echocardiography and can be used to perform volumetric measurements, the high costs, low accessibility and complexity of measurement are major disadvantages. Echocardiography is the most preferred imaging method used to evaluate patients with palpitation in daily clinical practice, and it can also be used to easily measure EFT with high reproducibility [34\& 35].

Carotid intima-media thickness (CIMT) is a surrogate marker for atherosclerosis and can be used to detect an accelerated disease process and subclinical disease [36]. Carotid intima-media thickness is greater in hemodialysis patients compared to the control group [37]. CIMT remained a consistent predictor of fatal cardiovascular events indicates that this measurement bears a prognostic value on the dialysis population; a $0.1-\mathrm{mm}$ increase in CIMT predicts a $24 \%$ higher risk for cardiovascular death [38\&39].

Carotid intima-media thickness (CIMT) is a potential indicator of subclinical atherosclerosis. Epicardial fat thickness (EpFT) is suggested as a new cardio metabolic risk factor. EpFT is associated with increased CIMT [40].

Atakan et al., found that epicardial fat thickness was significantly higher among HD patients compared to healthy controls. In addition, their study was the first to demonstrate an inverse correlation between EpFT and coronary flow reserve in these patients [41].

Turan et al, reported that EpFT was associated with carotid intima-media thickness, arterial stiffness and coronary artery calcification [42]. Also Turkmen et al, showed an association between EpFT volume and coronary artery calcification in dialysis patients [43].

\section{Aim of the Study}

The aim of our current study is to assess the association between EpFT, carotid intima-media thickness and left ventricular systolic and diastolic function and left ventricular mass index in patients with CKD undergoing hemodialysis to clarify the relationships between $\mathrm{EpF}$ and cardiovascular disease risk in these patients.

\section{Subjects and Methods}

Forty adult uremic patients from dialysis unit of Theodor Bilharz Research Institute were included in this study. All patients were treated by conventional hemodialysis, 3 sessions weekly, 4 hours each.

Patients with clinical signs of heart failure, atrial fibrillation, uncontrolled hypertension, liver diseases, severely anemic patients with $\mathrm{Hb}<10 \mathrm{~g} / \mathrm{dl}$ and patients with malignancy or active inflammation were excluded from the study.

Twenty (age and sex matched) healthy control subjects, selected from medical and paramedical staff were included in this study.

All patients were provided by informed consent, and the ethical committee of hospital approved this study.

All patients and controls in this study were subjected to the 
following:

--Full clinical examination.

--Laboratory investigation: blood samples were collected from all patients from the antecubital vein between 8:00 AM and 10:00 AM with the patient in a supine position after fasting for $12 \mathrm{hr}$. Plasma glucose, complete blood picture, liver functions (AST, ALT, and albumin), renal functions (urea and creatinine), serum total calcium, serum phosphorus, serum electrolytes (sodium and potassium), serum total cholesterol (TC), high-density lipoprotein cholesterol (HDL), low-density lipoprotein cholesterol (LDL), triglycerides (TG), and C-reactive protein (CRP) levels were determined.

--Electrocardiogram (ECG): resting 12-lead surface electrocardiogram was carried out to detect evidence of left ventricular hypertrophy, ischemic heart disease, pericarditis or pericardial effusion.

--Echocardiography: left atrial (LA) diameter, the LV enddiastolic and systolic diameters, interventricular septum thickness, LV posterior wall thickness, mitral inflow early rapid filling wave (E) velocity, peak velocity of the late filling wave due to atrial contraction (A), E/A ratio and $\mathrm{E}$ wave deceleration time were measured according to the American Society of Echocardiography guidelines using a high resolution (ALT 5000 HDI) Toshiba Nemo 30 scanner equipped with a $2.5 \mathrm{mHz}$ transducer [44]. The LV mass index was calculated from the LV end-diastolic diameter, interventricular septum thickness, and LV posterior wall thickness according to the method of Devereux et al. LVM $\mathrm{gm}=1.04 \times\left\{(\text { LVEDD }+ \text { IVST }+ \text { PWT })^{3}-\right.$ LVEDD $\left.^{3}\right\} \times 0.8$ +0.6 [45]. Doppler and color Doppler studies were performed to detect valvular heart disease [44].

--Epicardial fat thickness was identified as the echocardiographically free space between the outer wall of the myocardium and the visceral layer of the pericardium, and its thickness was measured perpendicularly to the free wall of the right ventricle at end-systole over 3 cardiac cycles. The mean value of 3 cardiac cycles from each echocardiographic view (including both parasternal long- and short-axis views) was recorded as the EpF thickness [46].

--Carotid Duplex: high resolution B mode ultrasonography of both the common carotid arteries were performed using an ultrasound machine (Toshiba Nemo 30 scanner) equipped with a $7.5 \mathrm{mHz}$ high resolution transducer. CIMT was defined as a low-level echo gray band that does not project into the arterial lumen [47] and was measured during enddiastole as the distance from the leading edge of the second echogenic line of the far walls of the distal segment of the common carotid artery, the carotid bifurcation, and the initial tract of internal carotid artery on both sides.

\section{Statistical Analysis}

Statistical analysis was performed using SPSS version 17. Data were expressed as the mean \pm standard deviation (SD) for numerical variables. $\mathrm{P} \leq 0.05$ was considered to be statistically significant and $\mathrm{P}<0.01$ was considered to be highly statistically significant.

\section{Results}

Forty adult uremic patients from dialysis unit of Theodor Bilharz Research Institute, (16 females and 24 males), were treated by conventional hemodialysis, 3 sessions weekly, 4 hours each and twenty (age and sex matched) healthy control subjects, selected from medical and paramedical staff were included in this study.

Demographic features of hemodialysis patients and healthy control subjects were demonstrated in (table1). There were highly significant increase in systolic and diastolic blood pressure and in percent of diabetes mellitus in hemodialysis patients compared to healthy control subjects.

There were highly significant increase in serum creatinine, urea and C-reactive protein and there were also significant increase in serum phosphorus and triglyceride in hemodialysis patients compared to healthy control subjects. There were also highly significant decrease in estimated glomerular filtration rate, serum calcium and high-density lipoprotein cholesterol in hemodialysis patients compared to healthy control subjects (table2).

Table 1. Demographic features of hemodialysis patients and healthy control subjects:

\begin{tabular}{|c|c|c|c|}
\hline & Dialysis & Control & \multirow{3}{*}{ Sig. } \\
\hline & Patients & $(n=20)$ & \\
\hline & \multicolumn{2}{|l|}{$(n=40)$} & \\
\hline \multicolumn{4}{|l|}{ Age (Yrs) } \\
\hline Range & $23-75$ & $25-70$ & \\
\hline Mean \pm SD & $56.07 \pm 11.87$ & $51.55 \pm 13.42$ & NS \\
\hline \multicolumn{4}{|l|}{ Sex } \\
\hline Male & $24(60 \%)$ & $11(55 \%)$ & NS \\
\hline Female & $16(40 \%)$ & $9(45 \%)$ & NS \\
\hline Weight(Kg) & $73.67 \pm 14.54$ & $79.35 \pm 13.87$ & NS \\
\hline $\mathrm{BMI}\left(\mathrm{Kg} / \mathrm{m}^{2}\right)$ & $25.58 \pm 5.0$ & $27.6 \pm 4.19$ & NS \\
\hline $\begin{array}{l}\text { Systolic blood } \\
\text { Pressure }(\mathrm{mmHg})\end{array}$ & $136.5 \pm 16.4$ & $112.1 \pm 7.6$ & HS \\
\hline $\begin{array}{l}\text { Diastolic blood } \\
\text { Pressure }(\mathrm{mmHg})\end{array}$ & $78.8 \pm 6.2$ & $69.2 \pm 3.8$ & HS \\
\hline $\operatorname{DM}(\%)$ & $75 \%$ & -- & HS \\
\hline DOD(Yrs) & $3.27 \pm 4.5$ & -- & \\
\hline
\end{tabular}

BMI, Body mass index; DOD, Duration of dialysis; DM, Diabetes Mellitus; NS, Non Significant; HS, Highly Significant $(\mathrm{P}<0.01)$.

Table 2. Biochemical Laboratory data of hemodialysis patients and healthy control subjects:

\begin{tabular}{|c|c|c|c|c|}
\hline & Dialysis Group & Control Group & \multirow{2}{*}{$P($ value $)$} & \multirow{2}{*}{ Sig. } \\
\hline & $(n=40)$ & $(n=20)$ & & \\
\hline S.Creatinine $(\mathrm{mg} / \mathrm{dl})$ & $7.815 \pm 2.783$ & $0.815 \pm 0.253$ & $<0.01$ & HS \\
\hline $\operatorname{Urea}(\mathrm{mg} / \mathrm{dl})$ & $113.85 \pm 34.542$ & $26.75 \pm 3.316$ & $<0.01$ & HS \\
\hline eGFR & $5.0 \pm 1.1$ & $98.8 \pm 25.87$ & $<0.01$ & HS \\
\hline S.Calcium(mg/dl) & $7.98 \pm 1.14$ & $9.13 \pm 0.675$ & $<0.01$ & HS \\
\hline S.Sodium $(\mathrm{mEq} / \mathrm{l})$ & $135.1 \pm 2.75$ & $134.83 \pm 2.75$ & & NS \\
\hline
\end{tabular}




\begin{tabular}{lllll}
\hline & Dialysis Group & Control Group & \multirow{2}{*}{ P(value) } & Sig. \\
\cline { 2 - 3 } & $\mathbf{( n = 4 0 )}$ & $\mathbf{( n = 2 0 )}$ & NS \\
\hline S.Potassium(mEq/l) & $4.568 \pm 0.690$ & $4.35 \pm 0.370$ & 0.02 & S \\
S.Phosphorus(mg/dl) & $4.82 \pm 1.53$ & $3.615 \pm 0.64$ & 0.439 & NS \\
S.Chlesterol(mg/dl) & $189.46 \pm 48.15$ & $187.9 \pm 20.39$ & 0.02 & S \\
Triglyceride(mg/dl) & $141.6 \pm 65.21$ & $102.8 \pm 19.63$ & $<0.01$ & HS \\
HDL(mg/dl) & $35.15 \pm 6.057$ & $42.95 \pm 3.167$ & 0.378 & NS \\
LDL(mg/dl) & $122.246 \pm 44.37$ & $120.55 \pm 23.10$ & $<0.01$ & HS \\
CRP(mg/l) & $7.3 \pm 2.6$ & $1.7 \pm 0.4$ & 2.4 & \\
\hline
\end{tabular}

eGFR, Estimated glomerular filtration rate; HDL, high-density lipoprotein cholesterol; LDL, low-density lipoprotein cholesterol; and CRP, C-reactive protein. HS, Highly significant; S, Significant; NS, Non significant

There were highly significant increase in posterior wall thickness, interventricular septum thickness, left ventricular mass, left ventricular mass index, left atrial diameter, carotid intima-media thickness and epicardial fat thickness and also there were significant increase in peak velocity of the late filling wave due to atrial contraction and deceleration time in hemodialysis patients compared to healthy control subjects. There were also highly significant decreased E/A ratio in hemodialysis patients compared to healthy control subjects (table3).

Table 3. Echocardiographic data of hemodialysis patients and healthy control subjects:

\begin{tabular}{lllll}
\hline & $\begin{array}{l}\text { Dialysis } \\
\text { Patients }\end{array}$ & $\begin{array}{l}\text { Control } \\
\text { Group }\end{array}$ & P(value) & Sig. \\
\cline { 2 - 4 } & $\mathbf{( n = 4 0 )}$ & $\mathbf{( n = 2 0 )}$ & & \\
\hline EF(\%) & $63.833 \pm 8.93$ & $68.86 \pm 3.31$ & 0.13 & NS \\
FS(\%) & $34.98 \pm 6.549$ & $38.66 \pm 3.45$ & 0.3 & NS \\
LVEDD(mm) & $52.92 \pm 7.88$ & $47.93 \pm 6.57$ & 0.52 & NS \\
LVESD(mm) & $34.85 \pm 8.29$ & $32.37 \pm 5.58$ & 0.483 & NS \\
PWT(mm) & $11.11 \pm 2.22$ & $8.7 \pm 1.06$ & $<0.01$ & HS \\
IVST(mm) & $11.24 \pm 2.43$ & $8.68 \pm 0.97$ & $<0.01$ & HS \\
LVM(gm) & $241.27 \pm 80.43$ & $142.35 \pm 42.43$ & $<0.01$ & HS \\
LVMI & $138.87 \pm 55.73$ & $74.8 \pm 16.4$ & $<0.01$ & HS \\
LA(mm) & $38 \pm 6.5$ & $35 \pm 5.3$ & $<0.01$ & HS \\
E velocity(m/s) & $0.58 \pm 0.26$ & $0.60 \pm 0.15$ & 0.104 & NS \\
A velocity(m/s) & $0.65 \pm 0.44$ & $0.59 \pm 0.17$ & 0.04 & S \\
DT(ms) & $198 \pm 67$ & $189 \pm 56$ & 0.014 & S \\
E/A & $0.9 \pm 0.4$ & $1.1 \pm 0.5$ & $<0.01$ & HS \\
CIMT(mm) & $12.2 \pm 1.9$ & $7.1 \pm 2.8$ & $<0.01$ & HS \\
EpFT(mm) & $5.41 \pm 1.81$ & $4.07 \pm 1.34$ & $<0.01$ & HS \\
\hline
\end{tabular}

EF, Ejection fraction; FS, Fraction shortening; LV EDD Left ventricular enddiastolic diameters; LVESD Left ventricular end-systolic diameters; PWT, posterior wall thickness; IVST, Interventricular septum thickness; LVM, Left ventricular mass; LVMI, Left ventricular mass index; LA, Left atrial diameter; E, mitral inflow early rapid filling wave velocity; A, peak velocity of the late filling wave due to atrial contraction; E/A ratio; DT, deceleration time; CIMT, Carotid intema-media thickness; and EpFT, Epicardial fat thickness. HS, Highly significant; S, Significant; NS, Non significant.

The variables correlated with EpFT in hemodialysis patients were age, body mass index, systolic and diastolic blood pressure, high-density lipoprotein cholesterol, CRP, left atrium diameter, left ventricular mass index, E/A ratio, deceleration time and carotid artery intima-media thickness (table 4).

Table 4. The univariate correlations of the epicardial fat thickness.

\begin{tabular}{lll}
\hline Variable & R & P \\
\hline Age & 0.265 & 0.02 \\
Body mass index & 0.315 & $<0.01$ \\
Systolic blood pressure & 0.368 & $<0.01$ \\
Diastolic blood pressure & 0.372 & $<0.01$ \\
High-density lipoprotein cholesterol & -0.312 & $<0.01$ \\
C reactive protein & 0.435 & $<0.01$ \\
Left atrium diameter & 0.356 & $<0.01$ \\
Left ventricular mass index & 0.354 & $<0.01$ \\
E/A ratio & -0.386 & $<0.01$ \\
Deceleration time & 0.374 & $<0.01$ \\
Carotid artery intima-media thickness & 0.479 & $<0.01$ \\
\hline
\end{tabular}

Significant; $(\mathrm{P}<0.05)$, Highly Significant $(\mathrm{P}<0.01)$.

Epicardial fat thickness in hemodialysis patients was significantly correlated positively with age, highly significantly correlated positively with body mass index, systolic and diastolic blood pressure, CRP, left atrium diameter, left ventricular mass index, deceleration time and carotid artery intima-media thickness and highly significantly correlated negatively with high-density lipoprotein cholesterol and E/A ratio.

\section{Discussion}

Traditional cardiovascular risk factors including diabetes, hypertension and dyslipidemia are common among hemodialysis patients. However the high prevalence of atherosclerosis and arterial calcification in hemodialysis patients is far beyond the explanation by common cardiovascular risk factors [48].

In our study, there were highly significant increase in systolic and diastolic blood pressure and in percent of diabetes mellitus in hemodialysis patients compared to healthy control subjects. Our study agrees with other studies which found that the prevalence of hypertension was $86 \%$ in hemodialysis patients and was $25 \%$ in general population [49\& 50]. When ambulatory blood pressure monitoring was used to assess systolic hypertension in hemodialysis population the prevalence was $73 \%$ [49]. Also our study agrees with other studies that reported that DM occurs among patients receiving dialysis at rates greater than in the general population [51-53].

In our study, there were highly significant increase in 
serum triglyceride and highly significant decrease in highdensity lipoprotein cholesterol in hemodialysis patients compared to healthy control subjects. Our study agrees with other studies which found that the renal dyslipidemia is reflected in an abnormal apolipoprotein (apo) profile and in the concentrations and composition of individual lipoprotein families [54, 55]. It is characterized by reduced concentrations of apoA-containing lipoproteins in highdensity lipoprotein (HDL) and increased concentrations of intact or partially metabolized triglyceride-rich apoBcontaining lipoproteins in VLDL, intermediate-density lipoprotein (IDL), and LDL [55, 56 ].There is a preferential increase in the levels of IDL and small dense LDL [57\&58]. The principal features of renal dyslipidemia remain essentially unchanged during $\mathrm{HD}$, but the expression of dyslipidemia can be moderately attenuated during long-term HD [59].

There is a strong association between chronic inflammation and dysregulation of calcium, phosphate, and the parathyroid hormone, which lead to coronary atherosclerosis, arterial calcification and cardiovascular complications in chronic hemodialysis patients [60, 61].

In the current study, there was a significant increase in serum phosphorus in patient group versus the control group. This is in agreement with the study done by Spasovski who stated that the abnormalities in bone and mineral metabolism in CKD patients regarding hypocalcemia and hyperphosphatemia are associated with an increased risk of fractures, vascular calcifications and cardiovascular disease (CVD) [62].

The inflammatory marker CRP exhibited highly significant elevation in hemodialysis patients versus the control group. In agreement with these results, Jeznach-Steinhagen et al., reported that there is evidence that hemodialysis patients are in a state of chronic inflammation with activation of $\mathrm{C}$ reactive protein and proinflammatory cytokines and is associated with increased oxidative stress and endothelial dysfunction [63].

In the current study, the echocardiographic data showed a highly statistically significant increase in interventricular septum thickness at end diastole (IVST),posterior wall thickness at end diastole (PWT) and left ventricular mass index (LVMI) in hemodialysis patients compared to the controls $(\mathrm{P}<0.01)$. Our study agrees with the study of Resic and his colleague [29] who found increased left ventricular wall thickness in $55.8 \%$ of patients on chronic hemodialysis compared to the control group [64]. Our study agrees also with recent studies which found a highly statistically significant increase in IVST, PWT and LVMI in hemodialysis patients compared to the controls $(\mathrm{P}<0.01)$ $[65,66]$.

The present study, revealed that carotid intima-media thickness (CIMT) was highly significantly increased in patients with chronic hemodialysis than the control group $(\mathrm{P}<0.01)$. Common carotid artery intima-media thickness, as a measure of coronary artery disease and subclinical vascular disease, was found to be increased in patients with chronic hemodialysis than the control group [67]. Also our study agrees with recent studies which found a highly statistically significant increase in CIMT in hemodialysis patients compared to the controls $(\mathrm{P}<0.01)[65,66]$.

Left ventricular diastolic heart failure would be expected more frequently among patients with end stage renal disease (ESRD) than in the general population due to the inflammation, fluid overload, hypertension, reninangiotensin-aldosterone system activation, and LV hypertrophy associated with ESRD [21].

In the current study left ventricular diastolic function (E/A ratio and deceleration time) showed significantly higher dysfunction in the dialysis group compared to the control group. These results are similar to those reported by Gagliardi and his colleagues that also found $70 \%$ of their studied hemodialysis patients have diastolic dysfunction [68]. This finding also agrees with Fathi and his colleagues, who reported impaired left ventricular diastolic velocity in patients with ESRD [69]. Manes and his colleagues, in their study of Left ventricular geometric patterns and cardiac function in patients with chronic renal failure undergoing hemodialysis also found that diastolic dysfunction was found in $87 \%$ of patients. The relatively higher percentage in their study may be explained by their enrollment of diabetic patients in their study [70].

The present study, revealed that epicardial fat thickness was highly significantly increased in hemodialysis group than the control group $(\mathrm{P}<0.01)$. Our study agrees with a recent study which demonstrated that EFT was significantly higher among HD patients compared to healthy controls [41].

In our current study, we measured the thickness of EpF by echocardiography. Malavazos et al. documented that echocardiographic measurement accurately estimates the actual amount of EpF, which could be a strong and independent predictor of myocardial fat. Echocardiographic EpF measurement has advantages for use in both clinical and research settings, including low cost, routine applicability, avoidance of exposure to radiation, and potential for monitoring therapeutic effects [46].

In our study we found that Epicardial fat thickness in hemodialysis patients was significantly correlated positively with age, highly significant correlated positively with body mass index, systolic and diastolic blood pressure, ,CRP, left atrium diameter, left ventricular mass index, deceleration time and carotid artery intima-media thickness and highly significantly correlated negatively with high-density lipoprotein cholesterol and E/A ratio. Diastolic dysfunction was represented by E/A ratio and deceleration time.

This is in agreement with the recent study of Kocyigit and his colleagues that showed highly significant positive correlation between epicardial fat thickness and these parameters in dialysis patients; age, body mass index, systolic and diastolic blood pressure and CRP [71]. Also in another recent study EpFT measured from parasternal long and short-axis showed statistically significant positive correlation with age $(\mathrm{r}=0.354, \mathrm{p}<0.001 ; \mathrm{r}=0.286, \mathrm{p}<0.001$ respectively), and waist circumference $(\mathrm{r}=0.189, \mathrm{p}=0.019$; 
$\mathrm{r}=0.217, \mathrm{p}=0.007$ respectively) and also significant negative correlation between EpFT from the parasternal long axis with cholesterol-HDL was observed $(\mathrm{r}=-0.163, \mathrm{p}=0.045)$ [72]. Epicardial fat thickness in other study found to be positively correlated with age and BMI [30]. Other study using univariate analysis demonstrated the strongest associations between EpF volume and body mass index (BMI) ( $\mathrm{r}=0.53$; $\mathrm{P}=<0.0001)$, abdominal obesity $(\mathrm{r}=0.51 ; \mathrm{P}<0.01)$ and high density lipoprotein (HDL) cholesterol $(\mathrm{r}=-0.39 ; \mathrm{P}=<0.01)$ [73].

In our study we found that epicardial fat thickness in hemodialysis patients was correlated highly significantly with left atrium diameter and this is in agreement with the study of Iacobellis et al., and that of Konishi et al., who found that epicardial fat thickness was correlated highly significantly with left diameter $(\mathrm{P}<0.01)[74,75]$.

Our study showed that epicardial fat thickness in hemodialysis patients was correlated highly significantly with left ventricular mass index. This is in agreement with Corradi et al. who thought that EpFT have an important role in left ventricular hypertrophy [32]. On the other hand, HDL had an independent negative relationship with LVM. HDL is a metabolic syndrome parameter and may represent it; therefore, absence of metabolic syndrome may be protective for increase in LVM [76- 78].

In the current study, we found that EpF thickness in patients undergoing HD correlates with left ventricular diastolic dysfunction (LVDD). This is in agreement with the study of .Van der Meer which showed that myocardial fat has progressive and harmful effects on LV diastolic function [79] $\mathrm{EpF}$ is characterized by a high rate of release of free fatty acids (FFA) [24], which encounter no physical barrier or fascia before reaching the cardiomyocytes; [25] therefore, the myocardium receives a double dose of FFA from both the $\mathrm{EpF}$ and the systemic circulation. There are also hypothesis that $\mathrm{EpF}$ can influence LV diastolic function. EpF is a source of several bioactive molecules that might directly influence the myocardium [80]. In metabolic and cardiovascular disease states, these fat tissues expand, becoming hypoxic and dysfunctional $[81,82]$ and recruiting phagocytic cells [83] which would lead to reducing the production of protective cytokines, increasing detrimental adipocytokines and impaired cardiac function eventually.

Our study revealed that EpF thickness in patients undergoing HD correlates with carotid intima-media thickness which agrees with a recently published study by Turan et al., who concluded that EpF volume is correlated with cardiovascular surrogate markers such as carotid intimamedia thickness and pulse-wave velocity [42]. In a study by Turkmen et al., the authors found a significant relationship between EpF volume and the presence of the malnutritioninflammation-atherosclerosis calcification syndrome in HD patients [30]. In another study by the same group, they reported a relationship between EpFT and coronary artery calcification among peritoneal dialysis patients [43]

A recent meta-analysis showed that EpFT may be an effective marker for the prediction of coronary heart disease
[84]. Epicardial fat thickness produces a large amount of cytokines and proinflammatory mediators such as tumor necrosis factor-alpha and interleukin- 6 , and it is believed to promote atherosclerosis via paracrine effects [85, 28]. The direct contact with the coronary arteries of an inflammed EpF may induce vasa vasorum proliferation that penetrate through the arterial wall toward the intima and promote atherosclerosis [86]. The proatherosclerotic activity of the $\mathrm{EpF}$ is indirectly suggested by its close association with vulnerable atherosclerotic plaques and the risk of incident cardiovascular event [87-90].

The mechanisms that promote the development of CAD through epicardial fat are not completely clear. The role of epicardial fat as a metabolically active organ with paracrine or endocrine functions is the most accepted. Previous studies have shown that adipose tissue, particularly visceral fat, express numerous genes related to adipokine production, which have important roles in the development of atherosclerosis in obese patients [28, 91]. Epicardial fat located near to the coronary tree could facilitate the paracrine effects of epicardial adipokines, as part of the pathogenesis of CAD [92\&93].

\section{Conclusion and Recommendation}

Hemodialysis patients can be evaluated routinely by echocardiography for early detection of structural and functional cardiovascular abnormalities which are common in these patients and may lead to high morbidity and mortality.

Epicardial fat thickness in hemodialysis patients is correlated significantly with left atrium diameter, left ventricular mass index, diastolic dysfunction (E/A ratio, deceleration time) and carotid artery intima-media thickness (which is an indicator of atherosclerosis). So, epicardial fat thickness which can be easily measured by Echocardiography is an effective marker for the prediction of cardiovascular disease risk in hemodialysis patients.

\section{References}

[1] Zhang QL and Rothenbacher D (2008): Prevalence of chronic kidney disease in population-based studies: systematic review. BMC Public Health 8:117.

[2] Foley RN, Parfrey PS and Sarnak MJ (1998): Epidemiology of cardiovascular disease in chronic renal disease. J Am. Soc. Nephro.1 9 (12 Suppl) S16-23.

[3] Block GA, Raggi P, Bellasi A, et al., (2007): Mortality effect of coronary calcification and phosphate binder choice in incident hemodialysis patients. Kid. Int. 71:438-441.

[4] Shantouf RS, Budoff MJ, Ahmadi N, et al., (2010): Total and individual coronary artery calcium scores as independent predictors of mortality in hemodialysis patients. Am J Nephrol 31:419-425.

[5] Watanabe R, Lemos MM, Manfredi SR, et al., (2010) : Impact of cardiovascular calcification in nondialyzed patients after 24 months of follow-up. Clin J Am Soc Nephrol 5:189-194. 
[6] Russo D, Corrao S, Battaglia Y, et al. (2011): Progression of coronary artery calcification and cardiac events in patients with chronic renal disease not receiving dialysis. Kid. Int. 80:112-118.

[7] Sarnak M. J., LeveyA. S., Schoolwerth A. C. et al., ( 2003) : "Kidney disease as a risk factor for development of Cardiovascular disease: a statement from the American Heart Association Councils on Kidney in Cardiovascular disease, High Blood Pressure Research, Clinical Cardiology, and Epidemiology and Prevention," Circulation, 108(17): 2154 2169.

[8] Muntner P., He J., Hamm L., et al., (2002): "Renal insufficiency and subsequent death resulting from cardiovascular disease in the United States," Journal of the American Society of Nephrology, 13( 3): 745-753.

[9] Foley R. N., Murray A. M., Li S., Herzog C. A., et al., (2005): "Chronic kidney disease and the risk for cardiovascular disease, renal replacement, and death in the United States medicare population, 1998 to 1999," Journal of the American Society of Nephrology, 16 (2):489-495.

[10] Rahman M., Pressel S., Davis B. R. et al., (2006): "Cardiovascular outcomes in high-risk hypertensive patients stratified by baseline glomerular filtration rate," Annals of InternalMedicine, 144(3): 172-180.

[11] Van Der Velde M., Matsushita k., Coresh J. et al., ( 2011): "Lower estimated glomerular filtration rate and higher albuminuria are associated with all-cause and cardiovascular mortality. A collaborative meta-analysis of high-risk population cohorts," Kid. Int., 79 (12): 1341-1352.

[12] Segura J., Campo C., Gil P. et al., (2004): "Development of chronic kidney disease and cardiovascular prognosis in essential hypertensive patients," Journal of the American Society of Nephrology, 15(6): 1616-1622.

[13] Knobler H, Zornitzki T, Vered S. et al., (2004): "Reduced glomerular filtration rate in asymptomatic diabetic patients: predictor of increased risk for cardiac events independent of albuminuria," Journal of the American College of Cardiology, 44, (11): 2142-2148.

[14] Antman E.M., Anbe D.T., Armstrong P.W. et al., (2004): "ACC/AHA guidelines for the management of patients with ST-elevation myocardial infarction. A report of the American College of cardiology/ American Heart Association Task Force on Practice Guidelines (Committee to Revise the 1999 Guidelines for the Management of patients with acute myocardial infarction)," Journal of the American College of Cardiology, 44(3): 1-211, 2004.

[15] Kalantar-Zadeh K., Block G., Humphreys M. H., et al., (2003): "Reverse epidemiology of cardiovascular risk factors in maintenance dialysis patients," Kid. 63(3): 793-808, 2003.

[16] Parfrey P.S., Foley R. N., Harnett J.D., et al., (1996): "Outcome and risk factors for left ventricular disorders in chronic uraemia," Nephrology Dialysis Transplantation, 11(7): $1277-1285$.

[17] Cheung A.K., Sarnak M. J., Yan G. et al., (2000):"Atherosclerotic cardiovascular disease risks in chronic hemodialysis patients," Kid. Int. 58 (1): 353-362.

[18] Muntner P., He J., Astor B.C., et al., (2005): “Traditional and nontraditional risk factors predict coronary heart disease in chronic kidney disease: results from the atherosclerosis risk in communities study," Journal of the American Society of Nephrology, 16(2): 529-538, 2005.

[19] Himmelfarb J., Stenvinkel P., Ikizler T.A., et al., (2002): "Perspectives in renal medicine: the elephant in uremia: oxidant stress as a unifying concept of cardiovascular disease in uremia," Kid. Int. 62(5): 1524-1538.

[20] Afsar B, Turkmen K, Covic A, et al., (2014): An Update on Coronary Artery Disease and Chronic Kidney Disease. International J Nephr, 9.

[21] Bajraktari G, Berbatovci-Ukimeraj M, Hajdari A, et al., (2009): Predictors of increased left ventricular filling pressure in dialysis patients with preserved left ventricular ejection fraction. Croat Med J 50: 543-549.

[22] Hirota H, Yoshida K, Kishimoto T, et al.,(1995): Continuous activation of gp130, a signal-transducing receptor component for interleukin 6-related cytokines, causes myocardial hypertrophy in mice. Proc Natl Acad Sci U S A, 92:48624866.

[23] Wu CK, Yang CY, Lin JW, et al., (2012): The relationship among central obesity, systemic inflammation, and left ventricular diastolic dysfunction as determined by structural equation modeling. Obesity (Silver Spring) 2012, 20:730-737.

[24] Marchington JM, Mattacks CA and Pond CM (1989): Adipose tissue in the mammalian heart and pericardium: structure, foetal development and biochemical properties. Comp Biochem Physiol B 94: 225-232.

[25] Iacobellis G, Corradi D and Sharma AM (2005): Epicardial adipose tissue: anatomic, biomolecular and clinical relationships with the heart. Nat. Clin. Pract. Cardiovasc. Med. 2:536-543.

[26] Kadowaki T, Yamauchi T, Kubota N, et al., (2006): Adiponectin and adiponectin receptors in insulin resistance, diabetes, and the metabolic syndrome.J Clin Invest 116: 17841792.

[27] Kern PA, Ranganathan S, Li C, et al., (2001): Adipose tissue tumor necrosis factor and interleukin-6 expression in human obesity and insulin resistance. Am J Physiol Endocrinol Metab, 745-751.

[28] Mazurek T, Zhang L, Zalewski A, et al., (2003): Human epicardial adipose tissue is a source of inflammatory mediators. Circulation 108:2460-2466.

[29] Tonbul HZ, Kultigin T, Kayikcioglu H, et al., (2011): Epicardial adipose tissue and coronary artery calcification in diabetic and nondiabetic end-stage renal disease patients. Ren Fail 33: 770-775.

[30] Turkmen K, Kayikcioglu H, Ozbek O, et al.,(2011): The relationship between epicardial adipose tissue and malnutrition, inflammation, atherosclerosis / calcification syndrome in ESRD patients. Clin J Am Soc Nephrol 6 (8):1920-1925.

[31] Alvarez Tamargo JA, Barriales Alvarez V, Sanmartin Pena JC, et al., (2001) :Angiographic correlates of the high-risk criteria for conventional exercise testing and the Duke treadmill score. Rev Esp Cardiol; 54: 860-7.

[32] Corradi D, Maestri R, Callegari S, et al., (2004): The ventricular epicardial fat is related to the myocardial mass in normal, ischemic and hypertrophic hearts. Cardiovasc Pathol; 13: 313-6. 
[33] Iacobellis G, Ribaudo MC, Zappaterreno A, et al., (2004): Relation between epicardial adipose tissue and left ventricular mass. Am J Cardiol; 94: 1084-7.

[34] Iacobellis G, Assael F, Ribaudo MC, et al., (2003): Epicardial fat from echocardiography: a new method for visceral adipose tissue prediction. Obes Res. 11(2):304-10.

[35] Aribas A, Akilli H, Kayrak M, et al., (2014): Echocardiographic Epicardial Fat Thickness in Patients with Paroxysmal Atrial Fibrillation. Exp Clin Cardiol 20(6) 3574-3586.

[36] Cobble $\mathrm{M}$ and Bale B., (2010): Carotid intima-media thickness: Knowledge and application to every day practice. Postgrad Med. 2010; 122 (1):10-18

[37] Ossareh S, Alaei A and Saedi D., (2011): Carotid intima-media thickness in maintenance hemodialysis patients: role of cardiovascular risk factor. Iran J Kidney; 5(3):169-174

[38] Francesco A B, Francesco M, Giovanni T et al.,(2001): Prognostic Value of Ultrasonographic Measurement of Carotid Intima Media Thickness in Dialysis Patients. J Am Soc Nephrol ; 12: 242-464.

[39] Saritas T, Tascilar E, Abaci A, et al.,(2010): Importance of plasma N-terminal pro B-type natriuretic peptide, epicardial adipose tissue, and carotid intima-media thicknesses in asymptomatic obese children. Pediatr Cardiol.; 31(6):79.

[40] Sengul C, Cevik C, Ozveren O, et al., (2011): Echocardiographic epicardial fat thickness is associated with carotid intima-media thickness in patients with metabolic syndrome. Echocardiography. 28 (8):853-8

[41] Atakan A, Macunluoglu B, Kaya Y, et al., (2014): Epicardial fat thickness is associated with impaired coronary flow reserve in hemodialysis patients. Hemodial Int. 18 (1): 62-9.

[42] Turan MN, Gungar O, Asci G et al., (2013): Epicardial adipose tissue volume and cardiovascular disease in hemodialysis patients. Atherosclerosis 226: 129-133.

[43] Turkmen K, Ozbek O, Kayikcioglu H et al,. (2012): The relationship between epicardial adipose tissue and coronary artery calcification in peritoneal dialysis patients. Cardiorenal Med. 2:43-51.

[44] Gottdiener J.S., Bendnarz I. and Devereaux R., (2004): American Society of Echocardiography recommendations for use of echocardiography inclinical trials. Journal of American Society of Echocardiography; 17: 1086: 1119

[45] Devereux RB, Alonso DR, Lutas EM, et al.,(1986): Echocardiographic assessment of left ventricular hypertrophy: comparison to necropsy findings. Am. J Cardiol. 57: 450-458.

[46] Malavazos AE, Di Leo G, Secchi F, et al., (2010): Relation of echocardiographic epicardial fat thickness and myocardial fat. Am J Cardiol 105:1831-1835

[47] Berglund GL, Riley WA, Barnes RW et al., (1994): Quality control in ultrasound studies on atherosclerosis. J. Int. Med. 236: $581-586$

[48] Longenecker JC, Coresh J, Powe NR, et al., (2002): Traditional cardiovascular disease risk factors in dialysis patients compared with the general population: the CHOICE Study. J Am Soc Nephrol.; 13: 1918-1927.

[49] Agarwal R. (2005): Hypertension in chronic kidney disease and dialysis: pathophysiology and management. Cardiol Clin.

\section{3: $237-248$.}

[50] Agarwal R, Andersen MJ, Bishu K, et al. (2006): Home blood pressure monitoring improves the diagnosis of hypertension in hemodialysis patients. Kidney Int. 69: 900-906.

[51] Salifu MO, Abbott KC, Aytug S, et al., (2010): New-onset diabetes after hemodialysis initiation: impact on survival. Am J Nephrol 31(3):239-46.

[52] Tien KJ, Lin ZZ, Chio CC, et al., (2013): Epidemiology and mortality of new-onset diabetes mellitus after dialysis: Taiwan national cohort study. Diabetes Care. 30. [Epub ahead of print]

[53] Woodward RS, Schnitzler MA, Baty J, et al., (2003): Incidence and cost of new onset diabetes mellitus among U.S. wait-listed and transplanted renal allograft recipients. Am J Transplant 3(5):590-8.

[54] Attman P-O, Samuelsson O and Alaupovic P(1993): Lipoprotein metabolism and renal failure. Am J Kidney Dis 21: 573-591.

55. Alaupovic P. ( 1991): Apolipoprotein composition as the basis for classify- ing plasma lipoproteins. Characterization of apoA- and apoB-con-taining lipoprotein families. Prog Lipid Res 30:105-138.

[55] Foley RN, Parfrey PS and Sarnak MJ (1998): Clinical epidemiology of cardiovascular disease in chronic renal disease. Am J Kidney Dis 32: 112-119.

[56] Attman P-O, Alaupovic P, Tavella M, et al., (1996): Abnormal lipid and apolipoprotein composition of major lipoprotein density classes in patients with chronic renal failure. Nephrol Dial Transplant 11: 63-69.

[57] Rajman I, Harper L, McPake D, et al. (1998): Low-density lipoprotein subfraction profiles in chronic renal failure. Nephrol Dial Trans plant 13: 2281-2287.

[58] Reddy E, Suchitra M, Reddy Vet al., (2008): Dyslipidemia: End Stage Renal Disease and Hemodialysis. Int. J. Neph. 5 (1)

[59] Lee CT, Tsai YC, Ng HY, et al., (2009): Association between $\mathrm{C}$-reactive protein and biomarkers of bone and mineral metabolism in chronic hemodialysis patients: A crosssectional study. J Ren Nutr; 19: 2227.

[60] Wang AY, Lam CW, Wang M, et al., (2008): Increased circulating inflammatory proteins predict a worse prognosis with valvular calcification inendstage renal disease: A prospective cohort study. Am J Nephrol; 28: 6653.

[61] Spasovski G. (2007): New aspects of treatment of renal bone disease in dialysis patients. Prilozi. 28(1):205-13.

[62] Jeznach-Steinhagen A, Słotwiński R and Szczygieł B. (2007): Malnutrition, inflammation, atherosclerosis in hemodialysis patients.Rocz Panstw Zakl Hig. 58(1):83-8.

[63] Resic H; Ajanovic S and Kukavica N (2009): Plasma levels of brain natriuretic peptides and cardiac troponin in hemodialysis patients. Bosn J. Basic Med Sci. 9(2):137-141.

[64] Abd El-khalik A A, Ameen M A R, Metwaly A A, et al., (2014): Cardiovascular Calcification in Chronic Hemodialysis Patients: Contributors Interplay. Am J Life Sci 2(5): 251-259.

[65] Waked E, El Shanawani F, Raafat M, et al., (2011): Bone Specific Alkaline Phosphatase and Cardiovascular Morbidity among Patients on Maintenance Hemodialysis. Life Science Journal, 8(4):1078- 1087. 
[66] Rampersaud E; Bielak LF; Persa A (2008): The association of coronary artery calcification and carotid artery intima-media thickness with distinct traditional coronary artery disease risk factors in asymptomatic adults. Am. J. of Epidemiology 168(9):1016-1023.

[67] Gagliardi GM, Rossi S, Manes MT, et al.(2004): Impact of left ventricular patterns and diastolic dysfunction on hemodialysis patients. G Ital Nefrol ; 21(1):45-50.

[68] Fathi, R., N. Isbel, B. Haluska, C. et al.,(2003): Correlates of subclinical left ventricular dysfunction in ESRD. Am. J. Kidney. Dis. 41: 1016- 1025.

[69] Manes MT, Gagliardi M, Misuraca G, et al.,(2005): Left ventricular geometric patterns and cardiac function in patients with chronic renal failure undergoing hemodialysis. Monaldi Arch Chest Dis: 64(1):27-32.

[70] Kocyigit I, Gungor O, Unal A, et al., (2014): A low serum triiodo-thyroxine level is association with epicardial adipose tissue in peritoneal dialysis patients. J. Atheroscler. Thromb. 21(10), 1066- 1074

[71] Yañez-RiveraT G, Baños-Gonzalez M A, Ble-Castillo J L, et al., (2014): Relationship between epicardial adipose tissue, coronary artery disease and adiponectin in a Mexican population. Cardiovascular Ultrasound, 12-35.

[72] Kerr J D, Holden R M, Morton AR, et al., (2013): Associations of epicardial fat with coronary calcification, insulin resistance, inflammation, and fibroblast growth factor23 in stage 3-5 chronic kidney disease. BMC Nephrology $14: 26$.

[73] Iacobellis G, Leonetti F, Singh N, et al., (2007): Relationship of epicardial adipose tissue with atrial dimensions and diastolic function in morbidly obese subjects. Int $\mathrm{J}$ Cardiol $115: 272-273$.

[74] Konishi M, Sugiyama S, Sugamura K et al ( 2012): Accumulation of pericardial fat correlates with left ventricular diastolic dysfunction in patients with normal ejection fraction Journal of Cardiology 59, (3): 344-351

[75] Yusuf S, Hawken S, Ounpuu S, et al.(2005): Obesity and the risk of myocardial infarction in 27,000 participants from 52 countries: a case-control study. Lancet 366: 1640-9.

[76] Guerra F, Mancinelli L, Buglioni A, et al. (2011): Microalbuminuria and left ventricular mass in overweight and obese hypertensive patients: role of the metabolic syndrome. High Blood Press. Cardiovasc. Prev. 18 : 195-201.

[77] Apridonidze T, Shaqra H, Ktaich N, et al., (2011): Relation of components of the metabolic syndrome to left ventricular geometry in hispanic and non-hispanic black adults. Am J Cardiovasc Dis 1: 84-91.

[78] Van der Meer RW, Rijzewijk LJ, Diamant M, et al., (2008): The ageing male heart: myocardial triglyceride content as independent predictor of diastolic function. Eur Heart J 29:1516-1522.
[79] Iozzo P (2011): Myocardial, perivascular, and epicardial fat. Diabetes Care 34(Suppl 2):S371-S379.

[80] Greenstein AS, Khavandi K, Withers SB, et al., (2009): Local inflammation and hypoxia abolish the protective anticontractile properties of perivascular fat in obese patients. Circulation 119: 1661-1670.

[81] Pang C, Gao Z, Yin J, et al., (2008): Macrophage infiltration into adipose tissue may promote angiogenesis for adipose tissue remodeling in obesity. Am J Physiol Endocrinol Metab 295:E313-E322.

[82] Henrichot E, Juge-Aubry CE, Pernin A, et al., (2005): Production of chemokines by perivascular adipose tissue: a role in the pathogenesis of atherosclerosis? Arterioscler Thromb Vasc Biol 25:2594-2599.

[83] Xu Y, Cheng X, Hong K, et al., (2012): How to interpret epicardial adipose tissue as a cause of coronary artery disease: a meta-analysis. Coronary Artery Dis 23: 227-233.

[84] Baker AR, Silva NF, Quinn DW et al., (2006): Human epicardial adipose tissue expresses a pathogenic profile of adipocytokines in patients with cardiovascular disease. Cardiovasc. Diabetol. 5: 1

[85] Subbotin VM. (2012): Neovascularization of coronary tunica intima (DIT) is the cause of coronary atherosclerosis. Lipoproteins invade coronary intima via neovascularization from adventitial vasa vasorum, but not from the arterial lumen: a hypothesis. Theor. Biol. Med. Model. 9: 11

[86] Alexopoulos N, McLean DS, Janik M et al.(2010): Epicardial adipose tissue and coronary artery plaque characteristics. Atherosclerosis 210: 150-154

[87] Tavora F, Kutys R, Li L et al.(2010): Adventitial lymphocytic inflammation in human coronary arteries with intimal atherosclerosis. Cardiovasc Pathol 19: 61-68

[88] Ding J, Hsu FC, Harris TB et al. (2009): The association of pericardial fat with incident coronary heart disease: the MultiEthnic Study of Atherosclerosis (MESA). Am J Clin Nutr 90: 499-504

[89] Mahabadi AA, Berg MH, Lehmann N et al. (2013): Association of epicardial fat with cardiovascular risk factors and incident myocardial infarction in the general population: the Heinz Nixdorf Recall Study. J Am Coll Cardiol 61: 13881395 .

[90] Chaldakov GN, Stankulov IS and Aloe L (2001): Subepicardial adipose tissue in human coronary atherosclerosis: another neglected phenomenon. Atherosclerosis 154:237-238.

[91] Maeda K, Okubo K, Shimomura I, et al., (1997): Analysis of an expression profile of genes in the human adipose tissue. Gene 190:227-235.

[92] Chaldakov GN, Beltowsky J, Ghenev PI, et al.,(2012): Adipoparacrinology-vascular periadventitial adipose tissue (tunica adiposa) as an example. Cell Biol Int 36:327-330. 